\title{
Factors associated with dental pain related to last dental visit among adult patients
}

\section{Czynniki związane z bólem stomatologicznym u pacjentów dorosłych podczas ostatniej wizyty w gabinecie dentystycznym}

\author{
Muhammad Ashraf Nazir ${ }^{A,-F}$ \\ Department of Preventive Dental Sciences, College of Dentistry, Imam Abdulrahman Bin Faisal University, Dammam, Saudi Arabia \\ A - research concept and design; B - collection and/or assembly of data; $C$ - data analysis and interpretation; \\ $D$ - writing the article; $E$ - critical revision of the article; $F$ - final approval of the article
}

Address for correspondence

Muhammad Nazir

E-mail:manazir@uod.edu.sa

\section{Funding sources}

None declared

Conflict of interest

None declared

Received on November 30, 2017

Reviewed on December 29, 2017

Accepted on January 17, 2018

DOI

$10.17219 / \mathrm{dmp} / 83039$

Copyright

() 2018 by Wroclaw Medical University

and Polish Dental Society

This is an article distributed under the terms of the

Creative Commons Attribution Non-Commercial License

(http://creativecommons.org/licenses/by-nc-nd/4.0/)

\begin{abstract}
Background. Most dental visits are made to seek dental care to relieve dental pain. However, the factors associated with behavior regarding dental visits due to pain are not fully understood.

Objectives. The objective of this study was to assess the factors associated with dental pain related to last dental visit among adults.

Material and methods. The data was obtained from a cross-sectional study conducted on adults, aged 18-69 years, who visited public and private dental clinics in Dammam, Saudi Arabia. A pilot-tested, self-administered questionnaire was employed for data collection. Dental pain related to last dental visit was a dependent variable in the study. Gender, age, nationality, income and education levels, time since last dental attendance, type of dental clinic visited, and chronic systemic disease were important independent variables. The Pearson's $x^{2}$ test and multiple logistic regression analysis were used.
\end{abstract}

Results. The participants returned 671 questionnaires. Most of the participants were females (75.4\%), and the majority (68.0\%) attended private dental clinics. The prevalence of dental pain as the reason of last dental visit was $70.4 \%$. A logistic regression model showed that odds ratio for subjects who visited the dentist due to pain in $\leq 1$ year was $0.34(95 \% \mathrm{Cl}=0.24,0.49)$ compared with patients who visited the dentist in $>1$ year. Similarly, male gender $(O R=0.64 ; 95 \% \mathrm{Cl}=0.42,0.97)$ subjects aged $\leq 35$ years $(O R=0.61$; $95 \% \mathrm{Cl}=0.40,0.95)$ were less likely to make pain-related dental appointments than females and individuals over 35 years. The respondents who attended private dental clinics were $1.56(95 \% \mathrm{Cl}=1.12,2.37)$ times more likely to visit the dentist because of pain than those who attended a public clinic

Conclusions. Delayed dental visits, female gender, age over 35 years, and private clinic attendance were significant factors associated with dental consultations motivated by pain.

Key words: adult patients, last dental visit, dental pain

Słowa kluczowe: pacjenci dorośli, ostatnia wizyta u stomatologa, ból stomatologiczny 


\section{Introduction}

The utilization of dental care is critical to achieving, maintaining and promoting oral health, general health and well-being of individuals. ${ }^{1}$ However, the past years have seen declining trends in the use of oral care services among adult populations, and it has decreased from $40.5 \%$ to $37 \%$ in the USA over a period of a decade (2001-2010)..$^{2,3}$ Generally, patients avoid visiting dentists due to the cost of treatment, lack of perceived need for oral care, lack of insurance, transportation difficulty, lack of time, and dental anxiety. ${ }^{3-5}$ Nevertheless, dental pain, a dental public health problem, is the predominant reason of dental attendance, and depending upon its duration and intensity, patients tend to take self-medication or visit a dental office, hospital emergency room, or physicians. ${ }^{6-8}$

Dental pain is the most common of different orofacial pains such as temporomandibular disorders, neuralgias and facial pains. ${ }^{9}$ It can negatively influence chewing, swallowing, speaking, smiling, and productivity, and most dental visits are made to relieve dental pain. ${ }^{10}$ In a national survey of Spanish general population, the prevalence of dental pain was $26.3 \%$ in adults aged $35-44$ years. ${ }^{11}$ The incidence of dental pain is also high, as a considerable percentage of individuals develop pain over a certain time period. For example, in a longitudinal study of a 2-year duration, $31.2 \%$ of subjects with no dental pain at the baseline developed dental pain. ${ }^{12}$ Dental caries is the leading cause of dental pain. ${ }^{13,14}$ In addition, pain frequently occurs as a result of abscess, loosening of teeth, bleeding gums, and broken teeth. ${ }^{14}$

According to Nuttal et al., $40 \%$ of dentate subjects suffered from pain during the last 1 year, which affected their activities of daily life. ${ }^{15}$ Compared with $3.5 \%$ of Chinese adults who attended the dentist for routine dental care, $84.1 \%$ visited a dental office due to a toothache. ${ }^{16}$ Fewer subjects (3\%) who sought care for a routine dental checkup reported poor oral health than $15 \%$ of those who visited the dentist when in trouble. ${ }^{17}$ Patients expressed poor satisfaction when they visited the dentist for pain relief. ${ }^{18}$ Moreover, a recent study documented that dental attendance due to trouble with teeth was associated with the impact on individuals' quality of life. ${ }^{19}$ Gender and race were found to be associated with the number of dental problems experienced during the last 10 years. ${ }^{6}$ Being a single parent, an immigrant, self-perception of poor oral health, and low income are the predictors of dental attendance motivated by pain..$^{20,21}$ Likewise, male gender, younger age ( $<30$ years) and high educational level were associated with preventive dental visits. ${ }^{16,22}$

While the factors related to different reasons of seeking dental care have been investigated, the available literature lacks a clear picture of the factors that influence oral care seeking behaviors of patients when in pain. Since most dental visits are made to relieve pain, understanding these underlying factors can help policy makers and other stakeholders develop appropriate oral health policies and pro- grams. The present study was set out to assess the factors that are associated with dental pain related to last dental visit among adult patients in Dammam, Saudi Arabia.

\section{Materials and methods}

This study presents a secondary analysis of data from self-administered questionnaires gathered from patients visiting private and public dental clinics in Dammam, Saudi Arabia. The ethical clearance (No. EA201713) was obtained from the Scientific Research Unit (an ethics committee) at the College of Dentistry, Imam Abdulrahman Bin Faisal University, Dammam, Saudi Arabia. Data collection started in March 2017 and was completed in August 2017. The study comprised a non-probabilistic sample, and patients who were willing to participate in the study were provided with questionnaires. The participants were informed about their right of voluntary participation and there were no consequences for them in case they refused to participate in the study. The objective of the study, including its potential benefits, was discussed with the participants. The study was conducted in full accordance with the World Medical Association Declaration of Helsinki. The patients were approached in person in the dental hospital of the college, and other public dental clinics and private practices in the city. They provided their consent by filling out the questionnaires. The questionnaire was developed in English and was translated into Arabic for its administration among Arab participants, while non-Arab study subjects received the English questionnaire. Piloting of the questionnaire was conducted on a group of patients to ensure its validity, feasibility and practicality. The privacy and confidentiality of patients were preserved during data collection, analysis and publication.

The participants' reasons of visiting a dental office were sought, and dental pain as the reason of last dental visit was the dependent variable in the present study. Age, gender, nationality, educational qualifications, income level, time since last dental visit, type of dental clinic visited, presence of chronic systemic disease, and family history of chronic systemic disease were the independent variables. Based on the participants' information, they were grouped into 3 income levels: low, middle and high. Educational qualification was categorized as high school education or less, and university education. The time since last dental visit included $<6$ months, 6 months -1 year and $>1$ year.

Field data was translated back into English and entered into a computer database. SPSS software (IBM SPSS Statistics for Windows v. 22; IBM Corp., Armonk, USA) was used for processing and analyzing the data. Percentages of participants were presented along with their confidence intervals $(\mathrm{CI})$. The study variables were dichotomized. The Pearson's $\chi^{2}$ test included bivariate analysis of participants' responses between those who visited the dentist because of dental pain and those with other reasons of dental at- 
tendance, and unadjusted odds ratios (OR) were calculated. Multiple logistic regression analysis was performed to calculate the adjusted odds ratios between 2 variables after controlling for other variables. Using backward stepwise logistic regression modeling, the final model with best predictive value was created. A 95\% confidence interval and $\mathrm{p}$-value $<0.05$ were used for statistical testing.

\section{Results}

The study sample consisted of 671 participants $(7.6 \%$ non-response or refusal). The age of the participants ranged from 18 years to 69 years with a mean age 33.6 \pm 12.1 years. More females $(75.4 \%)$ than males $(24.6 \%)$ participated in the study. Saudi respondents made up the predominant proportion (89.9\%) of the study sample. The prevalence of dental pain as the reason of last dental visit was $70.4 \%$, and $52.7 \%$ visited a dental office in $\leq 1$ year. Slightly less than a half belonged to low and middle income groups individually, and $67.4 \%$ had undergraduate degree or higher education. Most subjects (68.0\%) visited private dental clinics (Table 1).

Table 1. Distribution of responses of study participants

\begin{tabular}{|c|c|}
\hline Variables & Percentage $(95 \% \mathrm{CI})$ \\
\hline $\begin{array}{l}\text { Reasons of visiting dentist } \\
\text { pain } \\
\text { other reasons }\end{array}$ & $\begin{array}{l}70.4(66.9,73.8) \\
29.6(26.1,33.0)\end{array}$ \\
\hline $\begin{array}{l}\text { Time since last dental visit } \\
<6 \text { months } \\
6 \text { months }-1 \text { year } \\
>1 \text { year }\end{array}$ & $\begin{array}{c}9.6(7.4,11.8) \\
43.1(39.3,46.8) \\
47.3(43.5,51.1)\end{array}$ \\
\hline $\begin{array}{l}\text { Gender } \\
\text { male } \\
\text { female }\end{array}$ & $\begin{array}{l}24.6(21.3,27.8) \\
75.4(72.1,78.6)\end{array}$ \\
\hline $\begin{array}{l}\text { Age } \\
\begin{aligned} \leq 35 \\
>35\end{aligned}\end{array}$ & $\begin{array}{l}60.1(56.4,63.8) \\
39.9(36.2,43.6)\end{array}$ \\
\hline $\begin{array}{l}\text { Educational qualification } \\
\quad \leq \text { high school education } \\
\text { zundergraduate degree }\end{array}$ & $\begin{array}{l}32.6(29.0,36.1) \\
67.4(63.8,70.9)\end{array}$ \\
\hline $\begin{array}{l}\text { Income level } \\
\text { low income } \\
\text { middle income } \\
\text { high income }\end{array}$ & $\begin{array}{c}46.0(42.2,49.8) \\
45.5(41.7,49.3) \\
8.5(6.4,10.6)\end{array}$ \\
\hline $\begin{array}{l}\text { Nationality } \\
\text { Saudi } \\
\text { non-Saudi }\end{array}$ & $\begin{array}{c}89.9(87.6,92.2) \\
10.1(7.8,12.4)\end{array}$ \\
\hline $\begin{array}{l}\text { Type of clinic } \\
\text { private } \\
\text { public }\end{array}$ & $\begin{array}{l}68.0(64.5,71.5) \\
32.0(28.5,35.5)\end{array}$ \\
\hline $\begin{array}{l}\text { Presence of chronic systemic disease } \\
\text { yes } \\
\text { no }\end{array}$ & $\begin{array}{l}21.0(17.9,24.1) \\
79.0(75.9,82.1)\end{array}$ \\
\hline $\begin{array}{l}\text { Family history of chronic systemic disease } \\
\text { yes } \\
\text { no }\end{array}$ & $\begin{array}{l}62.4(58.7,66.1) \\
37.6(33.9,41.2)\end{array}$ \\
\hline
\end{tabular}

$\mathrm{Cl}$ - confidence interval.
Bivariate analysis of the data shows that younger age ( $\leq 35$ years), male gender and last dental visit in $\leq 1$ year had significantly lower OR of making last dental visit because of dental pain. On the other hand, attending a private dental clinic, presence of systemic chronic disease and family history of systemic chronic disease had significantly higher OR of pain-related dental attendance compared with those who visited a public clinic, who had no disease or family history of chronic systemic disease (Table 2).

Table 2. Bivariate analysis: factors associated with dental pain related to last dental visit

\begin{tabular}{|c|c|c|}
\hline \multirow{2}{*}{ Variables } & Unadjusted OR & \multirow{2}{*}{$\mathrm{p}$-value } \\
\hline & percentage $(95 \% \mathrm{CI})$ & \\
\hline $\begin{array}{l}\text { Time since last dental visit } \\
\quad \leq 1 \text { year } \\
>1 \text { year }\end{array}$ & $0.37(0.26,0.52)^{*}$ & $<0.001^{*}$ \\
\hline $\begin{array}{l}\text { Gender } \\
\text { male } \\
\text { female }\end{array}$ & $0.68(0.47,0.99)^{*}$ & $0.044^{*}$ \\
\hline 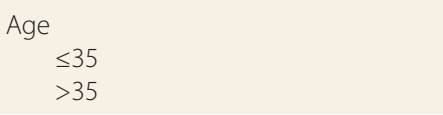 & $0.56(0.39,0.80)^{*}$ & $0.001^{*}$ \\
\hline $\begin{array}{l}\text { Educational qualification } \\
\leq \text { high school education } \\
\text { zundergraduate degree }\end{array}$ & $0.93(0.65,1.32)$ & 0.681 \\
\hline $\begin{array}{l}\text { Income level } \\
\qquad \text { low } \\
\geq \text { middle }\end{array}$ & $0.77(0.56,1.08)$ & 0.132 \\
\hline $\begin{array}{l}\text { Nationality } \\
\text { Saudi } \\
\text { non-Saudi }\end{array}$ & $0.75(0.42,1.34)$ & 0.333 \\
\hline $\begin{array}{l}\text { Type of clinic } \\
\text { private } \\
\text { public }\end{array}$ & $1.57(1.11,2.22)^{*}$ & $0.010^{*}$ \\
\hline $\begin{array}{l}\text { Presence of chronic systemic disease } \\
\text { yes } \\
\text { no }\end{array}$ & $1.69(1.09,2.62)^{*}$ & $0.018^{*}$ \\
\hline $\begin{array}{l}\text { Family history of chronic systemic disease } \\
\text { yes } \\
\text { no }\end{array}$ & $1.40(1.00,1.97)^{*}$ & $0.048^{*}$ \\
\hline
\end{tabular}

OR - odds ratio; $\mathrm{Cl}$ - confidence interval; * statistically significant.

Almost similar estimates of OR were observed when multiple logistic regression analysis was performed. The male respondents, those aged $\leq 35$ years, and who visited the dentist in $\leq 1$ year had significantly lower OR of dental pain as the reason of last dental visit than female patients, individuals $>35$ years and who performed dental visit in $>1$ year. The participants attending only a private dental clinic had significantly higher OR of seeking dental care due to pain than those who had a dental appointment in a public clinic. Income level, educational attainment, nationality, the presence of or family history of chronic systemic diseases were not significantly associated with pain-related patterns of dental attendance (Table 3). 
Table 3. Multivariate analysis: factors associated with dental pain-related last dental visits

\begin{tabular}{|c|c|c|}
\hline \multirow{2}{*}{ Variables } & Unadjusted OR & \multirow{2}{*}{$p$-value } \\
\hline & percentage $(95 \% \mathrm{Cl})$ & \\
\hline $\begin{array}{l}\text { Time since last dental visit } \\
\quad \leq 1 \text { year } \\
>1 \text { year }\end{array}$ & $0.34(0.24,0.49)^{*}$ & $<0.001^{*}$ \\
\hline $\begin{array}{l}\text { Gender } \\
\text { male } \\
\text { female }\end{array}$ & $0.64(0.42,0.97)^{*}$ & $0.033^{*}$ \\
\hline 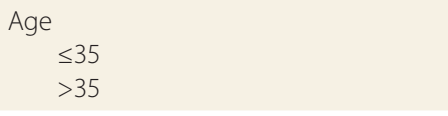 & $0.61(0.40,0.95)^{*}$ & $0.027^{*}$ \\
\hline $\begin{array}{l}\text { Educational qualification } \\
\quad \leq \text { high school education } \\
\quad \geq \text { undergraduate degree }\end{array}$ & $1.02(0.70,1.48)$ & 0.930 \\
\hline $\begin{array}{l}\text { Income level } \\
\text { low } \\
\geq \text { middle }\end{array}$ & $0.88(0.60,1.31)$ & 0.544 \\
\hline $\begin{array}{l}\text { Nationality } \\
\text { Saudi } \\
\text { non-Saudi }\end{array}$ & $0.62(0.33,1.16)$ & 0.137 \\
\hline $\begin{array}{l}\text { Type of clinic } \\
\text { private } \\
\text { public }\end{array}$ & $1.63(1.12,2.37)^{*}$ & $0.010^{*}$ \\
\hline $\begin{array}{l}\text { Presence of chronic systemic disease } \\
\text { yes } \\
\text { no }\end{array}$ & $1.51(0.92,2.49)$ & 0.101 \\
\hline $\begin{array}{l}\text { Family history of chronic systemic disease } \\
\text { yes } \\
\text { no }\end{array}$ & $1.27(0.88,1.83)$ & 0.203 \\
\hline
\end{tabular}

OR - odds ratio; Cl - confidence interval; * statistically significant.

Interaction/moderation analysis demonstrated no significant interactions between different variables of the study (Table 4). The backward stepwise final logistic regression model revealed that OR for subjects who visited the dentist due to pain in $\leq 1$ year was significantly lower $(\mathrm{OR}=0.34)$ compared with patients who had a dental appointment in $>1$ year. Likewise, male patients $(\mathrm{OR}=0.64)$

Table 4. Interaction/moderation analysis between different variables of the study

\begin{tabular}{|c|c|c|}
\hline \multirow{2}{*}{ Variables } & Unadjusted OR & \multirow{2}{*}{$p$-value } \\
\hline & percentage $(95 \% \mathrm{Cl})$ & \\
\hline $\begin{array}{l}\text { Time since last dental visit } \\
\text { Gender }\end{array}$ & $1.44(0.65,3.18)$ & 0.365 \\
\hline $\begin{array}{l}\text { Time since last dental visit } \\
\text { Age }\end{array}$ & $1.59(0.76,3.34)$ & 0.215 \\
\hline $\begin{array}{l}\text { Time since last dental visit } \\
\text { Type of clinic }\end{array}$ & $0.60(0.28,1.26)$ & 0.179 \\
\hline $\begin{array}{l}\text { Age } \\
\text { Gender }\end{array}$ & $0.80(0.37,1.74)$ & 0.583 \\
\hline $\begin{array}{l}\text { Age } \\
\text { Type of clinic }\end{array}$ & $1.04(0.50,2.16)$ & 0.907 \\
\hline $\begin{array}{l}\text { Gender } \\
\text { Type of clinic }\end{array}$ & $0.86(0.40,1.86)$ & 0.714 \\
\hline
\end{tabular}

OR - odds ratio; $\mathrm{Cl}$ - confidence interval; * statistically significant. and age $\leq 35$ years $(O R=0.61)$ had significantly lower $O R$ of making dental visits than females and patients $>35$ years. The participants who attended a private dental clinic were 1.56 times more likely to avail to dental services for pain than those who visited a public clinic (Table 5).

Table 5. Multiple logistic regression final model: factors associated with dental pain-related to last dental visit

\begin{tabular}{|c|c|c|}
\hline \multirow{2}{*}{ Variables } & Unadjusted OR & \multirow{2}{*}{$\mathrm{p}$-value } \\
\hline & percentage $(95 \% \mathrm{Cl})$ & \\
\hline $\begin{array}{l}\text { Time since last dental visit } \\
\quad \leq 1 \text { year } \\
>1 \text { year }\end{array}$ & $0.34(0.25,0.49)^{*}$ & $<0.001^{*}$ \\
\hline $\begin{array}{l}\text { Gender } \\
\text { male } \\
\text { female }\end{array}$ & $0.64(0.43,0.95)^{*}$ & $0.029^{*}$ \\
\hline 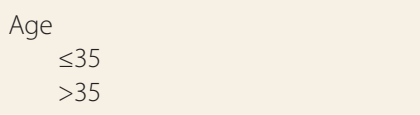 & $0.56(0.38,0.84)^{*}$ & $0.005^{*}$ \\
\hline $\begin{array}{l}\text { Type of clinic } \\
\text { private } \\
\text { public }\end{array}$ & $1.56(1.08,2.26)^{*}$ & $0.016^{*}$ \\
\hline $\begin{array}{l}\text { Presence of chronic systemic disease } \\
\text { yes } \\
\text { no }\end{array}$ & $1.56(0.95,2.54)$ & 0.076 \\
\hline
\end{tabular}

OR - odds ratio; Cl - confidence interval; * statistically significant.

\section{Discussion}

The present study described the factors that are associated with dental visits of patients suffering from dental pain. The understanding of these factors by health policy makers, educationists and dental professionals can improve access to oral care and minimize distressing sensations of pain experienced by most patients. It is known that poor utilization of dental services can delay a timely diagnosis, deteriorate oral conditions, compromise general health, and rarely lead to mortality. ${ }^{1}$

In the present study, dental pain as the reason of a dental visit was reported by $70.4 \%$ of subjects. This prevalent figure is lower than that reported by Liu et al., who found that $84.1 \%$ of adults visited a dental office due to a toothache. ${ }^{16}$ On the contrary, the results of the study by Lacerda et al. showed that $18.7 \%$ of patients attended a dental clinic to seek oral care to relieve pain. ${ }^{13}$ The authors pointed out that study participants had high access to dental services as they belonged to the working class, which could be the reason for such low prevalence. Similarly, Jaffar et al. observed that 1 in 4 industrial workers with pain seek dental treatment. ${ }^{23}$ Moreover, Ekanayake and Mendis reported that 23\% of patients who visited a dental teaching hospital required treatment because of dental pain. ${ }^{7}$ These discrepancies about prevalence estimates could be due to variations in data collection methods. ${ }^{13}$ In addition, the distribution of oral diseases which are the underlying causes of dental pain varies in different populations. ${ }^{14}$ 
When the relation between a dental pain-related visit and the time since last visit was analyzed, there was a 34\% lower chance of patients seeking dental attendance because of pain if individuals made a dental visit in $\leq 1$ year than in the case of a dental visit in $>1$ year. This finding is particularly significant, because the time duration between dental visits is essential for establishing evidence based recommendation for consulting a dentist in less than a year to avoid pain-related dental visits. Likewise, the previous study also demonstrated that individuals who performed regular dental visits for a routine checkup were 2.5 times less likely to experience dental pain. ${ }^{24}$ Regular access to dental services is usually suggested to get an early diagnosis and prevent complications of oral conditions.

Our study revealed that the type of dental clinic is another predictor of visiting the dentist as a result of feeling dental pain. The individuals with access to private dental care were more likely $(\mathrm{OR}=1.56)$ to perform a dental visit due to pain than those who used dental services in a public clinic. Dental pain is a disturbing experience that requires patients to seek immediate access to dental care and better quality of services. High patient satisfaction and improved quality of dental services were reported in private dental practices. ${ }^{25}$ However, private oral care services are limited to a relatively small proportion of the population compared with the public sector that provides preventive services in addition to curative care to most people in the country. ${ }^{26}$ On the contrary, the private sector broadly targets patients that require more esthetic, restorative and curative treatments. This might explain the reason why patients visiting private clinics have higher chances of making pain-related dental visits in Saudi Arabia.

The dental care utilization is more common in females than in males, and the female gender has higher chances for dental pain than their male counterparts. ${ }^{27,28}$ In contrast, men were 1.6 times more likely to report dental pain compared with women, and men were more likely to visit the dentist. ${ }^{20,24}$ In the present study, males were less likely than females to visit a dental office to seek pain relief. Two explanations can be formulated to provide the basis for a discussion regarding these gender differences. Firstly, dental caries and tooth loss, common reasons of dental pain, are more prevalent in women than in men. ${ }^{29,30} \mathrm{Sec}-$ ondly, pain perception varies between male and female genders as females tend to have a lower threshold and tolerance to pain than males. In addition, gender differences in pain can be related to social norms of pain expression and underlying biological mechanisms. ${ }^{31}$ Therefore, women with a high prevalence of caries and tooth loss, and low pain threshold are susceptible to pain experience, and consequently perform frequent dental visits.

The findings of our study revealed that subjects aged $\leq 35$ years compared with individuals older than 35 years had lower odds $(\mathrm{OR}=0.56)$ of dental consultation related to dental pain. In Saudi Arabia, lower caries experience $(\mathrm{DMFT}=14.5)$ has been documented in adults aged
35-44 years than in older individuals of mean age 62 years $(\mathrm{DMFT}=24.3) .{ }^{32}$ Similarly, the prevalence of tooth loss increases with age, culminating in a sharp rise in individuals in their seventies. ${ }^{30}$ It is reasonable to consider that a low distribution of caries experience and tooth loss in younger adults accounts for lower chances of seeking dental care because of pain. On the contrary, the studies have identified more young adults experiencing dental pain, which declined with advancing age. ${ }^{21,33,34}$ These inconsistencies in age-related pain perceptions can be ascribed to the subjective nature of pain, which is influenced by patient's knowledge, belief, expectations, and culture. ${ }^{13}$

There was no significant influence of income and education on dental attendance in the present study. Patterns of dental visits are often associated with high education and income levels. ${ }^{16,20}$ However, these factors may not have an influence on pain as the reason for dental visits. While our study provided valuable data, there are certain weaknesses that should be considered in interpreting study results. High estimates of prevalence of dental pain as a reason of dental visits in the present study can be attributed to data collection from dental clinics as opposed to a study with a random sample of adult population from the community. Typically for survey research, there is a possibility of recall bias due to inaccuracy in recollections about past experiences such as previous dental visits. Moreover, attention should be paid when generalizing these findings to patients who visit dental offices in other geographical locations of the country. It is suggested that a comparative study should be conducted using the same methods in another country in the future.

\section{Conclusions}

Based on the data analyzed in the present study, it can be concluded that subjects who sought dental care in less than a year had lower chances of pain-related dental attendance. Similarly, males and young adults were less likely to receive dental consultation due to pain. Finally, there was a higher possibility of performing a dental visit because of dental pain if individuals had access to a private rather than public dental clinic. These findings particularly suggest enabling these subjects to use dental health services by improving accessibility of such services and oral health literacy, and by changing patient perception of the importance of oral care.

\section{References}

1. Institute of Medicine and National Research Council. Improving Access to Oral Health Care for Vulnerable and Underserved Populations. Washington, DC: National Academies Press; 2011.

2. Vujicic M, Nasseh K. A decade in dental care utilization among adults and children (2001-2010). Health Serv Res. 2014;49:460-480.

3. Wall TP, Vujicic M, Nasseh K. Recent trends in the utilization of dental care in the United States. J Dent Educ. 2012;76:1020-1027.

4. Yarbrough C, Nasseh K, Vujicic M. Why adults forgo dental care: Evi- 
dence from a new national survey. Health Policy Institute Research Brief. American Dental Association (ADA). 2014. Available from: https://www.ada.org/ /media/ADA/Science\%20and\%20Research/ HPI/Files/HPIBrief_1114_1.ashx. Accessed August 16, 2017.

5. Locker D, Maggirias J, Quiñonez C. Income, dental insurance coverage, and financial barriers to dental care among Canadian adults. J Public Health Dent. 2011;71:327-334.

6. Cohen LA, Bonito AJ, Eicheldinger C, et al. Behavioral and socioeconomic correlates of dental problem experience and patterns of health care-seeking. J Am Dent Assoc. 2011;142:137-149.

7. Ekanayake L, Mendis R. Self reported use of dental services among employed adults in Sri Lanka. Int Dent J. 2002;52:151-155.

8. Macfarlane TV, Blinkhorn AS, Davies RM, Kincey J, Worthington HV. Factors associated with health care seeking behaviour for orofacial pain in the general population. Community Dent Health. 2003;20:20-26.

9. Horst OV, Cunha-Cruz J, Zhou L, et al. Prevalence of pain in the orofacial regions in patients visiting general dentists in the Northwest Practice-based REsearch Collaborative in Evidence-based DENTistry research network. J Am Dent Assoc. 2015;146:721-728.

10. Devaraj C, Eswar P. Reasons for use and non-use of dental services among people visiting a dental college hospital in India: A descriptive cross-sectional study. Eur J Dent. 2012;6:422-427.

11. Montero J, Bravo M, Lopez-Valverde A, Llodra JC. Clinical and sociodemographic predictors of oral pain and eating problems among adult and senior Spaniards in the national survey performed in 2010. Med Oral Patol Oral Cir Bucal. 2015;20:e393-401.

12. Duncan RP, Gilbert GH, Peek CW, Heft MW. The dynamics of toothache pain and dental services utilization: 24-month incidence. J Public Health Dent. 2003;63:227-234.

13. Lacerda JT, Simionato EM, Peres KG, et al. Dental pain as the reason for visiting a dentist in a Brazilian adult population. Rev Saude Publ. 2004;38:453-458.

14. Petersen PE, Bourgeois D, Ogawa H, Estupinan-Day S, Ndiaye C. The global burden of oral diseases and risks to oral health. Bull World Health Organ. 2005;83:661-669.

15. Nuttall NM, Steele JG, Pine CM, White D, Pitts NB. The impact of oral health on people in the UK in 1998. Br Dent J. 2001;190:121-126.

16. Liu L, Zhang Y, Wu W, Cheng R. Characteristics of dental care-seeking behavior and related sociodemographic factors in a middleaged and elderly population in northeast China. BMC Oral Health. 2015;15:66.

17. Afonso-Souza G, Nadanovsky P, Chor D, et al. Association between routine visits for dental checkup and self-perceived oral health in an adult population in Rio de Janeiro: The Pro-Saude Study. Community Dent Oral Epidemiol. 2007;35:393-400.

18. Hashim R. Patient satisfaction with dental services at Ajman University, United Arab Emirates. East Mediterr Health J. 2005;11:913-921.

19. Gaewkhiew P, Bernabe E, Gallagher JE, Klass C, Delgado-Angulo EK. Oral impacts on quality of life and problem-oriented attendance among South East London adults. Health Qual Life Outcomes. 2017;15:82.

20. Muirhead VE, Quinonez C, Figueiredo R, Locker D. Predictors of dental care utilization among working poor Canadians. Community Dent Oral Epidemiol. 2009;37:199-208.

21. Kuhnen M, Peres MA, Masiero AV, Peres KG. Toothache and associated factors in Brazilian adults: A cross-sectional population-based study. BMC Oral Health. 2009;9:7.

22. Al-Shammari KF, Al-Ansari JM, Al-Khabbaz AK, Honkala S. Barriers to seeking preventive dental care by Kuwaiti adults. Med Princ Pract. 2007;16:413-419.

23. Jaafar N, Razak IA, Zain RB. The social impact of oral and facial pain in an industrial population. Ann Acad Med Singapore. 1989;18:553-555.

24. Alexandre GC, Nadanovsky P, Lopes CS, Faerstein E. Prevalence and factors associated with dental pain that prevents the performance of routine tasks by civil servants in Rio de Janeiro, Brazil. Cad Saude Publ. 2006;22:1073-1078.

25. Handelman SL, Fan-Hsu J, Proskin HM. Patient satisfaction in four types of dental practice. J Am Dent Assoc. 1990;121:624-630.

26. Al-Jaber A, Da'ar OB. Primary health care centers, extent of challenges and demand for oral health care in Riyadh, Saudi Arabia. BMC Health Serv Res. 2016;16:628.
27. Brown LJ, Lazar V. Dental care utilization: How saturated is the patient market? J Am Dent Assoc. 1999;130:573-580.

28. Bastos JL, Gigante DP, Peres KG. Toothache prevalence and associated factors: A population based study in southern Brazil. Oral Dis. 2008;14:320-326.

29. Urzua I, Mendoza C, Arteaga O, et al. Dental caries prevalence and tooth loss in Chilean adult population: First national dental examination survey. Int J Dent. 2012;2012:810170.

30. Kassebaum NJ, Bernabe E, Dahiya M, et al. Global burden of severe tooth loss: A systematic review and meta-analysis. J Dent Res. 2014;93:20S-28S.

31. Dao TT, LeResche L. Gender differences in pain. J Orofac Pain. 2000;14:169-184.

32. Al-Ansari AA. Prevalence, severity, and secular trends of dental caries among various saudi populations: A literature review. SJMMS. 2014;2:142.

33. Brown TT, Finlayson TL, Fulton BD, Jahedi S. The demand for dental care and financial barriers in accessing care among adults in California. J Calif Dent Assoc. 2009;37:539-547.

34. Vargas CM, Macek MD, Marcus SE. Sociodemographic correlates of tooth pain among adults: United States, 1989. Pain. 2000;85:87-92. 